\title{
A INFLUÊNCIA DOS BASALTOS E DE MISTURAS COM ÁGUAS DE AQÜÍFEROS SOTOPOSTOS NAS ÁGUAS SUBTERRÂNEAS DO SISTEMA AQÜÍFERO SERRA- GERAL NA BACIA DO RIO PIQUIRI, PARANÁ - BR
}

\author{
André Virmond Lima Bittencourt ${ }^{1}$ \\ Ernani Francisco da Rosa Filho ${ }^{1}$ \\ Eduardo Chemas Hindi ${ }^{1}$ \\ Antonio Carlos Buchmann Filho ${ }^{1}$
}

\begin{abstract}
RESUMO
Os principais processos de condicionamento do quimismo das águas do aqüífero Serra Geral na bacia hidrográfica do rio Piquiri são a dissolução dos basaltos e equilíbrio com minerais secundários, bem como misturas com águas de aqüíferos sotopostos. Condições hidráulicas favoráveis quando associadas a descontinuidades geológicas em escala regional, possibilitam a ascensão de águas armazenadas no Sistema Aqüífero Guarani (SAG) para o Sistema Aqüífero Serra Geral na bacia hidrográfica do Piquiri, localizada no Estado do Paraná-Brasil. O SAG, neste caso, recarrega o aqüífero superior. Em situações onde o SAG encontra-se com elevadas concentrações de sulfato, assim como de outras substâncias, em condições piezométricas adequadas, poços que secionam apenas os basaltos passam a produzir águas misturadas, às vezes com características inadequadas ao consumo humano. Este processo resulta numa contaminação natural do Sistema Aqüífero Serra Geral. As águas nos basaltos estão armazenadas nas estruturas tectônicas, pelas quais ocorre a sua circulação. Na ausência de mistura com águas de aqüíferos subjacentes, as águas deste aqüífero são de excelente qualidade visto que o índice de precipitação na região varia entre 1200 a $1400 \mathrm{~mm} / \mathrm{ano}$. O íon predominante do sistema Aqǘfero Serra Geral é o bicarbonato cujo teor médio é de $48,95 \mathrm{mg} / \mathrm{L}$. O pH médio é de 7,32 sendo a média para os sólidos totais dissolvidos (STD) 103,27 mg/L. A média de cloretos é de 1,39 $\mathrm{mg} / \mathrm{L}$, atingindo um valor máximo de $6 \mathrm{mg} / \mathrm{L}$. O sulfato possui teor médio de 2,47 mg/L, sem ultrapassar o teor de $6 \mathrm{mg} / \mathrm{L}$. O cálcio possui um teor médio de $9,78 \mathrm{mg} / \mathrm{L}$, sendo que 52,5 $\%$ das amostras apresentam teores inferiores a $10 \mathrm{mg} / \mathrm{L}$ e 96,7 \% estão abaixo de $20 \mathrm{mg} / \mathrm{L}$. O sódio possui uma média de $8,49 \mathrm{mg} / \mathrm{L}$, sendo que $85,3 \%$ das amostras estão abaixo de $15 \mathrm{mg} / \mathrm{L}$. Definiu-se três classes para as águas dos poços perfurados no sistema Aqüífero Serra Geral, na região de abrangência da bacia hidrográfica do Piquiri, a saber: 1) águas bicarbonatadas cálcicas (62,2\% das amostras); 2) águas bicarbonatadas cálcio sódicas e bicarbonatadas cálcio magnesianas (22,9 \% das amostras); 3) águas bicarbonatadas sódicas (11,4 \% das amostras - são águas provenientes dos aqüíferos subjacentes). Foram encontradas ainda, duas amostras de águas bicarbonatadas magnesianas (3,5\%), porém neste caso foram consideradas como exceção em face de sua pouca significância.
\end{abstract}

Palavras-Chave: aqüífero fissurado, hidroquímica, basalto, sistema aqüífero Serra Geral

\begin{abstract}
The mains processes of responsible for the chemical characteristics of Serra Geral aquifer are the basalt weathering and equilibrium reactions with secondary minerals and mixing with underlayered aquifers. Favorable hydraulic conditions, when associated with regional geological discontinuities, induce the ascension of the waters stored in the Guarani Aqüifer System (SAG) to the Serra Geral basaltic aquifer. The same process occurs, at Piquiri river watershed in Paraná State, Southern Brazil the target of this case study. This process can lead to a decreasing in the water quality, when some natural contaminants come together with the water by tectonic fractures. The presence of fluorine in SAG is known, and the

\footnotetext{
${ }^{1}$ LPH - Laboratório de Pesquisas Hidrogeológicas, UFPR. Centro Politécnico - Jardim das Américas; Cx. Postal 19001; CEP: 81531-990 Curitiba - PR, Brasil.
} 
contribution of water coming from deeper aquifers in Serra Geral wells is suggested by the presence of Sulfate and sodium - bicarbonate waters. With a $\mathrm{pH}$ ranging around 7,32, the dominant ion in Serra Geral Aqüifer System is the bicarbonate $(48,95 \mathrm{mg} / \mathrm{L})$, and the calcium $(9,78 \mathrm{mg} / \mathrm{L})$ is the major cation. Sodium $(8,5 \mathrm{mg} / \mathrm{L})$ is present under $15 \mathrm{mg} / \mathrm{L}$ in $85 \%$ of the cases and the chloride mean is $1,39 \mathrm{mg} / \mathrm{L}$ with $8,5 \mathrm{mg} / \mathrm{L}$ mean. The magnesium is present also in low values $(2,42 \mathrm{mg} / \mathrm{L})$. The chemical character of waters is mainly calcium bicarbonate and calcium-magnesium, waters that acquire more and more a sodium characteristic with increasing mixing with under-basalt waters. This process is the same observed in other hydrographic basins in Paraná State. The Piquiri wells composition and mixing processes can be seen in plotting the water samples compositions in Piper diagram and in a cation triangular diagram whith draws of the waters families limited by lines representing the inter cationic relations (PRIC).

Key-words: fractured aquifer, hydrochemistry, basalt waters, Serra Geral aquifer System

\section{INTRODUÇÃO}

O Sistema Aqüífero Guarani (SAG), um dos maiores reservatórios de águas subterrâneas do mundo, é considerado no Brasil como sendo o conjunto das formações Botucatu e Pirambóia. Em algumas regiões este manancial armazena água com alguns parâmetros físico-químicos ultrapassando os limites mínimos estabelecidos para o abastecimento público. Vários poços perfurados neste aqüífero, por outro lado, produzem vazões excepcionais de águas de excelente qualidade, da ordem de até $800.000 \mathrm{~L} / \mathrm{h}$, com temperaturas, em alguns casos, superiores a $40^{\circ} \mathrm{C}$.

A Formação Serra Geral, sobreposta ao SAG, comporta o maior número de poços perfurados, até a presente data, sendo, por esta razão, a atual e a principal fonte de abastecimento de água subterrânea das cidades localizadas sobre a Bacia Sedimentar do Paraná na região do Sul do Brasil. Estas águas estão armazenadas nas estruturas tectônicas através das quais ocorre a sua circulação. São águas de excelente qualidade sendo o reservatório subterrâneo recarregado por uma precipitação que varia entre 1200 e 1400 $\mathrm{mm} / \mathrm{ano}$. A recarga atmosférica é acrescida pelas águas que ascendem, por descontinuidades geológicas, dos aqüíferos subjacentes sob elevada pressão hidráulica.

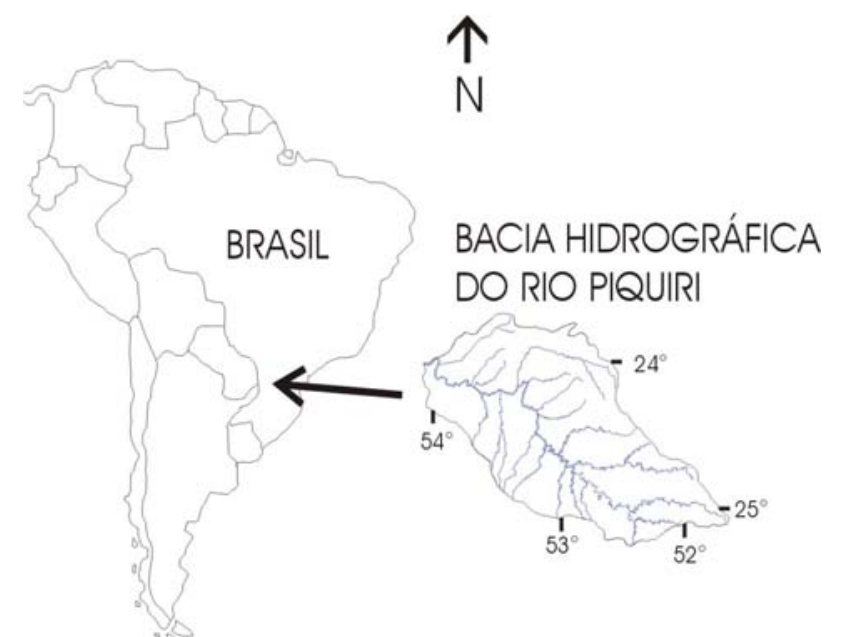

Figura 1. Localização da bacia hidrográfica do rio Piquiri.

\section{CONTEXTO GEOLÓGICO}

A bacia hidrográfica do rio Piquiri, objeto desta abordagem (Figura 1), é assentada sobre duas unidades geológicas aflorantes que são as Formações Serra Geral e também unidades supra-basálticas arenosas, destacando-se a Formação
Caiuá, que ocorrem em $15 \%$ da superfície da bacia e se localizam em sua porção nordeste (Figura 3 ) (POPP E BIGARELLA, 1975) e (FERNANDES, 1992).

As rochas da Formação Serra Geral apresentam textura micro-cristalina e uma estrutura que reflete a gênese através de 
derrames de lava sucessivos e intermitentes (LEINZ, 1949). Os derrames constituem unidades superpostas, de extensão lateral e continuidade vertical, limitados como conseqüência do movimento, resfriamento e conteúdo em gases da lava. A estrutura dos derrames pode ser caracterizada por uma zona basal, uma zona intermediária e uma zona de topo de derrame vesicular e/ou amidalóide (ROSA FILHO et. al., 1987). A espessura dessa sequência de derrames alcança aproximadamente $1000 \mathrm{~m}$ nas regiões centrais da Bacia do Paraná (REBOUÇAS, 1994).

De acordo com RÜEG (1969), a composição mineralógica predominante dos basaltos é formada por plagioclásios, augita e pigeonita. Ocorrem como minerais acessórios, outros silicatos e óxidos contendo principalmente alumínio, ferro, cálcio, magnésio, sódio, titânio e potássio.

É notável uma compartimentação estrutural regional, delineada por falhamentos e fraturamentos, bem como por diques de diabásio associados ao Arco de Ponta Grossa (VIEIRA, 1973; FERREIRA, 1981; 1982 e SOARES et al., 1981). O efeito das estruturas sobre a drenagem é especialmente evidente nas modificações de curso dos rios Goio Erê, Goio Bang, Xambrê e outros afluentes, além do próprio rio Piquiri. Este aspecto caracteriza uma influência na permeabilidade dos basaltos e em sua vulnerabilidade ao intemperismo (BITTENCOURT, 1993)

\section{CONTEXTO HIDROGEOLÓGICO}

O armazenamento e a circulação da água subterrânea no Sistema Aqüífero Serra Geral estão associados às descontinuidades geológicas das rochas, o que configura este reservatório subterrâneo como sendo um meio heterogêneo e anisotrópico (REBOUÇAS, 1978). Esta característica leva a que o meio apresente uma condutividade hidráulica muito variável e de complexa avaliação.

Estudos realizados nesse contexto, BITTENCOURT (1978), FRAGA (1986, 1992), ROSA FILHO et al. (1987) e CELLIGOI (1994), identificaram a tipologia da água deste aqüífero como sendo bicarbonatada cálcica. Os autores atribuem a composição bicarbonatada sódica de algumas águas captadas em poços com profundidades máximas de $200 \mathrm{~m}$, a uma mistura com as águas de aqüíferos subjacentes, a exemplo do aqüífero Guarani e aqüíferos paleozóicos.

\section{SEQÜÊNCIA METODOLÓGICA}

O presente estudo foi desenvolvido com base em análises da água constantes dos bancos de dados da SUDERHSA e SANEPAR. A despeito das análises contemplarem outros parâmetros, considerou-se nesta abordagem, a temperatura, o potencial hidrogeniônico, os sólidos totais dissolvidos, o bicarbonato, a sílica dissolvida, o cálcio, o magnésio, o sódio, o cloreto e o sulfato. Foram selecionadas as análises físico-químicas coletadas em poços georreferenciados que apresentaram erros inferiores a $10 \%$ no balanço iônico. A interpretação das classes geoquímicas foi feita com base na locação das análises em diagrama de Piper (HEM, 1970). Todos os poços catalogados estão georreferenciados.

\section{RESULTADOS OBTIDOS \\ Características físico-químicas}

De um universo de 381 registros, apenas 61 análises de águas foram consideradas adequadas para avaliação. Muitas das análises não contemplaram todos os macro-constituintes iônicos dissolvidos.

A temperatura da água dos poços, varia de um mínimo de $18,0{ }^{\circ} \mathrm{C}$ até o máximo de $22,5^{\circ} \mathrm{C}$, com a média situandose em $21,01^{\circ} \mathrm{C}$.

$\mathrm{O} \mathrm{pH}$ apresenta um valor médio igual 7,32 , variando entre 6 e 9,50. Os valores acima de 8 ocorrem em 13,1\% dos poços, são atribuídos a mistura com águas de aqüíferos subjacentes, principalmente 0 aqüífero Guarani (ROSA FILHO et al., 1987). Potenciais de hidrogênio superiores a 8,3 são responsáveis pela presença do íon $\mathrm{CO}_{3}{ }^{2+} \mathrm{e}$, conseqüentemente pela depleção dos teores de $\mathrm{Ca}^{2+}$, precipitado como calcita.

Para os sólidos totais dissolvidos (STD), os valores variam entre 23 e 210 $\mathrm{mg} / \mathrm{L}$, sendo a média igual a 103,37 mg/L. Em cerca de $50 \%$ das amostras o teor varia entre 100 e 150mg/L. Os componentes dissolvidos estão diretamente ligados ao tempo de residência da água no aqüífero, daí a variação de 10 vezes entre o limite mínimo e o máximo, ressalvando-se os possíveis casos de contaminação com soluções de outros aqüíferos. 
Os teores de sílica dissolvida variam entre 8 e $63 \mathrm{mg} / \mathrm{L}$, sendo o teor médio igual a $25,97 \mathrm{mg} / \mathrm{L}$. Em $62,7 \%$ das amostras o teor varia entre 10 e $25 \mathrm{mg} / \mathrm{L}$. A solubilidade da sílica é diretamente proporcional à temperatura, todavia a temperaturas no entorno de $20{ }^{\circ} \mathrm{C}$, por fatores cinéticos, são comuns teores em sílica superiores ao equilíbrio com o quartzo (cerca de 10 ppm), que é o que ocorre com a maioria das águas em questão. Em todo o caso sabe-se que a solubilidade da sílica é função não apenas da temperatura mas também do $\mathrm{pH}, \mathrm{a}$ despeito do último influenciar mais sensivelmente apenas a valores mais elevados ( $\mathrm{pH}>9)$ FRITZ(1981). Isto posto, fica evidente que a maioria das águas em contacto com os basaltos tem uma tendência de precipitar a sílica, seja como quartzo, calcedônia ou outros silicatos, porém a reação é mais lenta do que a intemperização da rocha primária. Estes aspectos conduzem a que sejam encontrados teores de sílica superiores àqueles do equilíbrio com a forma cristalizada menos solúvel de sílica, que é o quartzo.

O bicarbonato é o ânion mais abundante nessas águas. A concentração média é de 48,95 mg/L, com uma variação entre 6 e 127 mg/L. Em 82 \% das amostras, a concentração é inferior a $75 \mathrm{mg} / \mathrm{L}$. Esta é uma característica bastante comum em se tratando de águas continentais relativamente diluídas. O caráter bicarbonático é diretamente influenciado pelo equilíbrio do sistema $\mathrm{CO}_{2}-\mathrm{H}_{2} \mathrm{O}$ vigente nas áreas próximas à recarga porém também pelas reações de hidrólise dos silicatos das efusivas. Uma relação linear do teor em bicarbonatos com a salinidade para águas da Formação Serra Geral foi observada por BITTENCOURT (1978). As águas com teores mais baixos são aquelas de recarga mais recente.

A concentração de cloretos apresenta como teor médio $1,39 \mathrm{mg} / \mathrm{L}$, sendo que a sua variação está dentro do limite de 0,01 a
$6 \mathrm{mg} / \mathrm{L}$. Em 73,3 \% das amostras, o teor de cloretos é inferior a $1 \mathrm{mg} / \mathrm{L}$. Este fato corrobora o que foi observado por BITTENCOURT (1978) em águas da bacia do rio Ivaí, atribuído ao baixo teor em $\mathrm{Cl}$ dos basaltos e pequeno aporte cíclico, por veiculação atmosférica.

O teor médio de sulfatos é igual a 2,47 $\mathrm{mg} / \mathrm{L}$, variando de 1 a $6 \mathrm{mg} / \mathrm{L}$. Predominam teores inferiores a $3 \mathrm{mg} / \mathrm{L}$, o quais, em termos percentuais corresponde a 84,1\% das amostras. As efusivas da Bacia do Paraná são muito pobres em sulfetos e outras formas de enxofre e isto é refletido nos baixos teores em sulfato observado. Atribuem-se os teores mais elevados, a contaminações por águas oriundas de aqüíferos subjacentes.

O teor médio de cálcio é de $9,78 \mathrm{mg} / \mathrm{L}$, apresentando número máximo e mínimo respectivamente de 28,82 e 0,65 mg/L. Em $96,7 \%$ das amostras os valores são inferiores a $20 \mathrm{mg} / \mathrm{L}$, sendo que os intervalos de maior concentração ocorrem entre 5 e 15 $\mathrm{mg} / \mathrm{L}, \quad$ o que corresponde a $42 \%$ das amostras. A calcita é a grande controladora dos teores deste elemento em águas com $\mathrm{pH}$ alcalino

O teor médio do magnésio é de 2,42 $\mathrm{mg} / \mathrm{L}$, sendo que a variação é de 0,12 a 9,65 $\mathrm{mg} / \mathrm{L}$. Em $93,4 \%$ das águas os teores situam-se abaixo de $5 \mathrm{mg} / \mathrm{L}$. A contribuição deste íon é sobretudo proveniente dos ferromagnesianos do basalto, outras fontes acredita-se serem exceções

Quanto ao sódio, seu teor médio é de $8,49 \mathrm{mg} / \mathrm{L}$. Em mais de $85 \%$ das amostras os teores são inferiores a $15 \mathrm{mg} / \mathrm{L}$. Os teores mais elevados foram detectados nas amostras dos poços de Jesuítas e Formosa do Oeste, correspondem a 55,85 e 56,91 $\mathrm{mg} / \mathrm{L}$, respectivamente. As respectivas profundidades das entradas de água destes poços correspondem a 126 e $84 \mathrm{~m}$.

Os resultados das análises fisicoquímicas, em termos estatísticos, são apresentados na tabela 01. 


\begin{tabular}{|c|c|c|c|c|c|c|c|c|c|c|c|}
\hline \multirow[t]{2}{*}{ PARÂMETROS } & \multicolumn{11}{|c|}{ VARIÁVEIS } \\
\hline & $\mathrm{pH}$ & $\begin{array}{c}\text { STD } \\
(\mathrm{mg} / \mathrm{L})\end{array}$ & $\begin{array}{c}\text { temp } \\
\left({ }^{\circ} \mathrm{C}\right)\end{array}$ & $\begin{array}{l}\mathrm{HCO}_{3}^{-} \\
(\mathrm{mg} / \mathrm{L})\end{array}$ & $\begin{array}{c}\mathrm{Cl}^{-} \\
(\mathrm{mg} / \\
\mathrm{L})\end{array}$ & $\begin{array}{c}\mathrm{SO}^{-} \\
(\mathrm{mg} / \\
\mathrm{L})\end{array}$ & $\begin{array}{c}\mathrm{Ca}^{++} \\
(\mathrm{mg} / \\
\mathrm{L})\end{array}$ & $\begin{array}{c}\mathrm{Na}^{+} \\
(\mathrm{mg} / \mathrm{L})\end{array}$ & $\begin{array}{c}\mathrm{K}^{+} \\
(\mathrm{mg} / \mathrm{L})\end{array}$ & $\begin{array}{c}\mathrm{Mg}^{++} \\
(\mathrm{mg} / \mathrm{L})\end{array}$ & $\begin{array}{c}\mathrm{SiO}_{2} \\
(\mathrm{mg} / \mathrm{L})\end{array}$ \\
\hline Méc & 32 & & & & 1,39 & 2,47 & 9,78 & 8, & 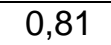 & & 2597 \\
\hline Med & 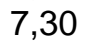 & 95 & 21,00 & 45 & 1,00 & 2,00 & 9,74 & 4,68 & 0,71 & 2,04 & 23,00 \\
\hline Desvio Padrão & 9,56 & 43,49 & 5,64 & 51,82 & 77,85 & 61,05 & 57,84 & 137,76 & 62,62 & 66,59 & 48,97 \\
\hline Máximo & 9,50 & 210,00 & 22,50 & 127,00 & 6,00 & 6,00 & 28,82 & 56,91 & 2,95 & 9,65 & 63,00 \\
\hline & 6,00 & 23,00 & 18,00 & 6,00 & 0,01 & 1,00 & 0,65 & 0,60 & 0,10 & 0,12 & 8,00 \\
\hline n. ${ }^{\circ} \mathrm{de} \mathrm{a}$ & 61 & 59 & 45 & 61 & 45 & 13 & 61 & 61 & 61 & 61 & 59 \\
\hline
\end{tabular}

Tabela 1. Resumo estatístico dos dados físico-químicos.

\section{Caracterização geral das águas}

A caracterização geral das águas foi apoiada no diagrama de Piper (Figura 02) que é adequado para salientar a influência dos macro-constituintes iônicos das águas naturais. Este diagrama também se caracteriza por evidenciar possíveis processos de mistura de águas diferentes.
Todas as amostras de água situam-se no campo das águas bicarbonatadas. A maior concentração dos pontos ocorre no campo das águas cálcicas e/ou cálcio magnesianas, algumas com tendência mista cálcio-sódica. Sete amostras situam-se no campo das águas sódicas.

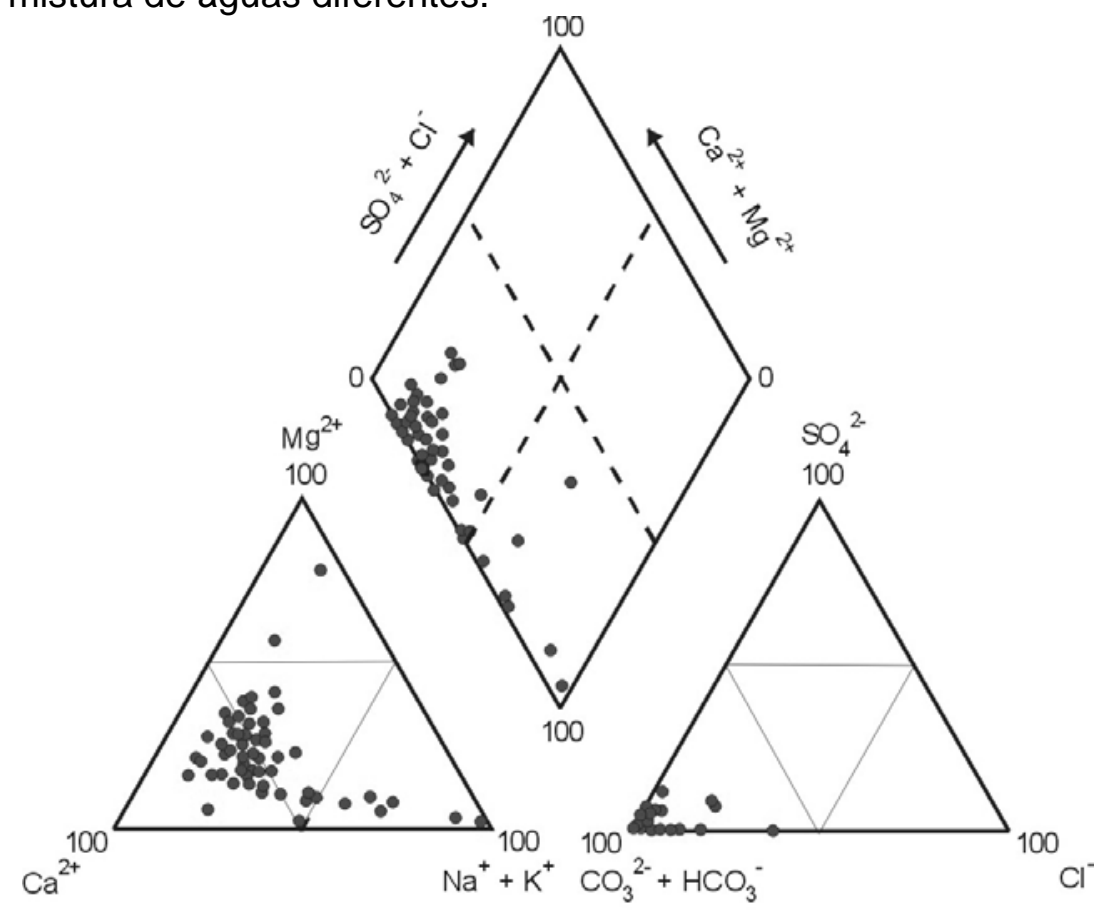

Figura 2. Diagrama de Piper para as águas de poços do Sistema Aqüífero Serra Geral na bacia do rio Piquiri.

As águas classificadas como bicarbonatadas cálcicas dos poços da bacia do Piquiri representam 62,2 \% das amostras (38 registros). Esta característica está diretamente ligada ao arcabouço químicomineralógico do aqüífero. O cálcio, presente sobretudo na forma $\mathrm{Ca}^{2+}$, é o cátion mais abundante. Isto é o reflexo de sua facilidade de remoção dos plagioclásios e ferromagnesianos dos basaltos. A mobilidade deste elemento foi salientada em trabalhos realizados na natureza (LEVI e MELFI, 1972) e em experimentos com intemperizadores, (HYPOLITO, 1972), com rochas básicas da Bacia do Paraná.

A solubilidade do $\mathrm{Ca}^{2+}$ em águas naturais está muito relacionada à presença de espécies carbônicas dissolvidas como: $\mathrm{H}_{2} \mathrm{CO}_{3}, \mathrm{HCO}_{3}{ }^{-}$e $\mathrm{CO}_{3}{ }^{2-}$. É sabido que a presença dominante de uma ou outra destes 
compostos está diretamente ligada ao $\mathrm{pH}$. $\mathrm{Na}$ faixa de $\mathrm{pH}$ que ocorre no contexto estudado, próximo à neutralidade, há o predomínio do íon bicarbonato, gerado diretamente por decomposição do ácido carbônico ou como produto da hidrólise dos silicatos do basalto. Daí as águas bicarbonatadas cálcicas. Com base em 106 amostras de águas naturais relacionadas a rochas basálticas coletadas no Estado do Paraná, BITTENCOURT (1978) obteve a relação $\log \left(\mathrm{Ca}^{2+}\right)=\log \left(\mathrm{HCO}_{3}{ }^{-}\right)-0,76$. Utilizando-se desta relação, para o teor médio de bicarbonato observado, 48,95 $\mathrm{mg} / \mathrm{L}$, teremos um valor calculado pela fórmula, de $8,85 \mathrm{mg} / \mathrm{L}$ de $\mathrm{Ca}^{2+}$, próximo à média observada de 9,78 mg/L.

As águas bicarbonatadas sódicas da bacia do Piquiri ocorrem em 7 poços, representando $11,4 \%$ do total de amostras utilizadas. $\mathrm{O} \mathrm{pH}$ é maior do que $8 \mathrm{em}$ cinco dessas amostras, o que as caracteriza como sendo águas alcalinas. Um dos poços que possui $\mathrm{pH}$ igual a 7 apresenta uma relação de " $\mathrm{ran}{ }^{+} / \mathrm{Ca}^{2+"}$ maior que 1 . O teor de sódio, nestes casos, é da ordem de $2,4 \mathrm{mg} / \mathrm{L}$ e de cálcio em torno de 1,04 mg/L. As profundidades dos poços são inferiores a $100 \mathrm{~m}$ e os os conteúdos de STD são inferiores a $30 \mathrm{mg} / \mathrm{L}$. Para o restante das amostras, a relação $\mathrm{r} \mathrm{Na}^{+} / \mathrm{Ca}^{2+}$ é sempre maior que 1 , com a maioria dos os teores sódio variando entre $20 \mathrm{mg} / \mathrm{L}$ e $56,9 \mathrm{mg} / \mathrm{L}$, ainda que o teor mais elevado é de 210 $\mathrm{mg} / \mathrm{L}$.

Águas bicarbonatadas sódicas estão em nítido desequilíbrio com aquilo que seria de se esperar para um aqüífero suportado por rochas basálticas. São águas com quimismo formatado provavelmente em ambiente externo ao aqüífero Serra Geral. Em águas superficiais o sódio é freqüentemente atribuído a contaminações antrópicas, o que pode ocorrer em alguns poços pouco profundos e água residindo por pouco tempo no aqüífero. Na maioria dos casos o ambiente alcalino é quem eleva a relação $\mathrm{Na}^{+} / \mathrm{Ca}^{2+}$ pela insolubilização do cálcio e também do magnésio. O ambiente do Guarani em condições de confinamento é típico destas condições. Neste contexto não se pode descartar a influência de unidades aqüíferas paleozóicas subjacentes acessadas também por estruturas tectônicas.
As águas de constituição mista englobam sete amostras de água bicarbonatada cálcio sódica e sete amostras de água bicarbonatada cálcio magnesiana, perfazendo $22,9 \%$ do total dos registros existentes na bacia hidrográfica do Piquiri. Esta tipologia é bastante comum em águas subterrâneas toda a formação Serra Geral no Estado do Paraná. Composições tendendo para o pólo sódico, como já foi mencionado, sugerem contribuição de fontes infrabasálticas, enquanto que teores maiores de magnésio podem perfeitamente se relacionar apenas com próprios basaltos.

\section{DIFERENCIAÇÕES HIDROQUÍMICAS}

Uma comparação com o caráter químico de corpos de água afins, apresentados em outros trabalhos é apresentada na Figura 3, que corresponde ao triângulo dos cátions do Diagrama de Piper. Estão registrados os Polígonos de Relações Intercatiônicas (PRIC) relativos a águas de uma drenagem unicamente sobre rochas basálticas e às análises consideradas neste trabalho. O córrego Jacutinga afluente do rio Ivaí, obtido de BITTENCOURT (1978), representa águas sobre os basaltos da Formação Serra Geral. $\mathrm{Na}$ construção dos polígonos não se considerou as amostras com valores extremos máximos e mínimos, com respeito às relações $\mathrm{rCa}^{2+} / \mathrm{rMg}^{2+}$ e $\mathrm{rMg}^{2+} / \mathrm{r}\left(\mathrm{Na}^{+}+\mathrm{K}^{+}\right)$. Para as águas das bacias do Piquiri, não se considerou também, as análises correspondentes a águas sódicas.

O quadro que se observa é de uma composição, em termos de macroconstituintes dissolvidos, muito semelhante ao observado em outras bacias, como as do Tibagi e do Ivaí para as águas subterrâneas no compartimento Serra Geral (BITTENCOURT, 1978), (ROSA $\mathrm{F}^{\circ}$ et al. 1987) e outros. Nos casos citados, é nítido o fato de águas cálcicas e cálciomagnesianas, tipicamente afins aos basaltos, tenderem para águas sódicas, mediante misturas crescentes de soluções vindas de aqüíferos subjacentes.

A distribuição das amostras utilizadas na bacia do Piquiri é razoavelmente uniforme, conforme pode ser visualizado na Figura 04. Este quadro também ocorreu no caso dos poços da bacia do Tibagi (dados inéditos). 


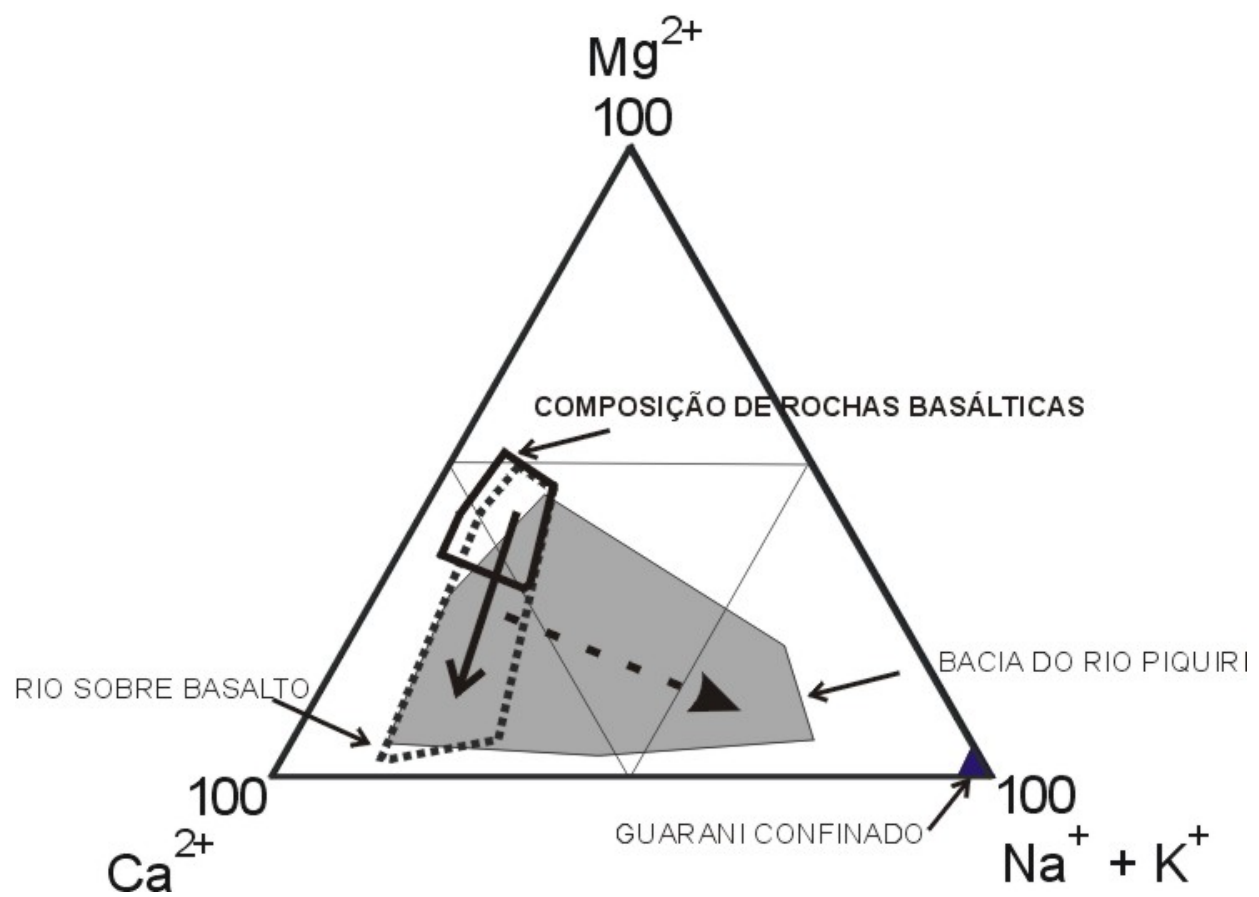

Figura 03: Variações nos teores de elementos alcalinos e alcalino-terrosos em águas relacionadas a rochas basálticas, promovidas por solubilização de basaltos, formação de minerais secundários e misturas com águas de aqüíferos sotopostos. Estão apresentados os Polígonos de Relações Intercatiônicas (PRIC) de águas de rio sobre basalto(córrego Jacutinga) e de águas subterrâneas da bacia do Piquiri coletadas em poços sobre basaltos. Foi construído polígono equivalente correspondente ao $\mathrm{Ca}, \mathrm{Mg}, \mathrm{Na}$ e $\mathrm{K}$ e de 47 rochas basálticas da coleção de RÜEGG (1969). O diagrama foi construído com dados em percentuais de meq /L para águas e meq $/ \mathrm{kg}$ para rochas.

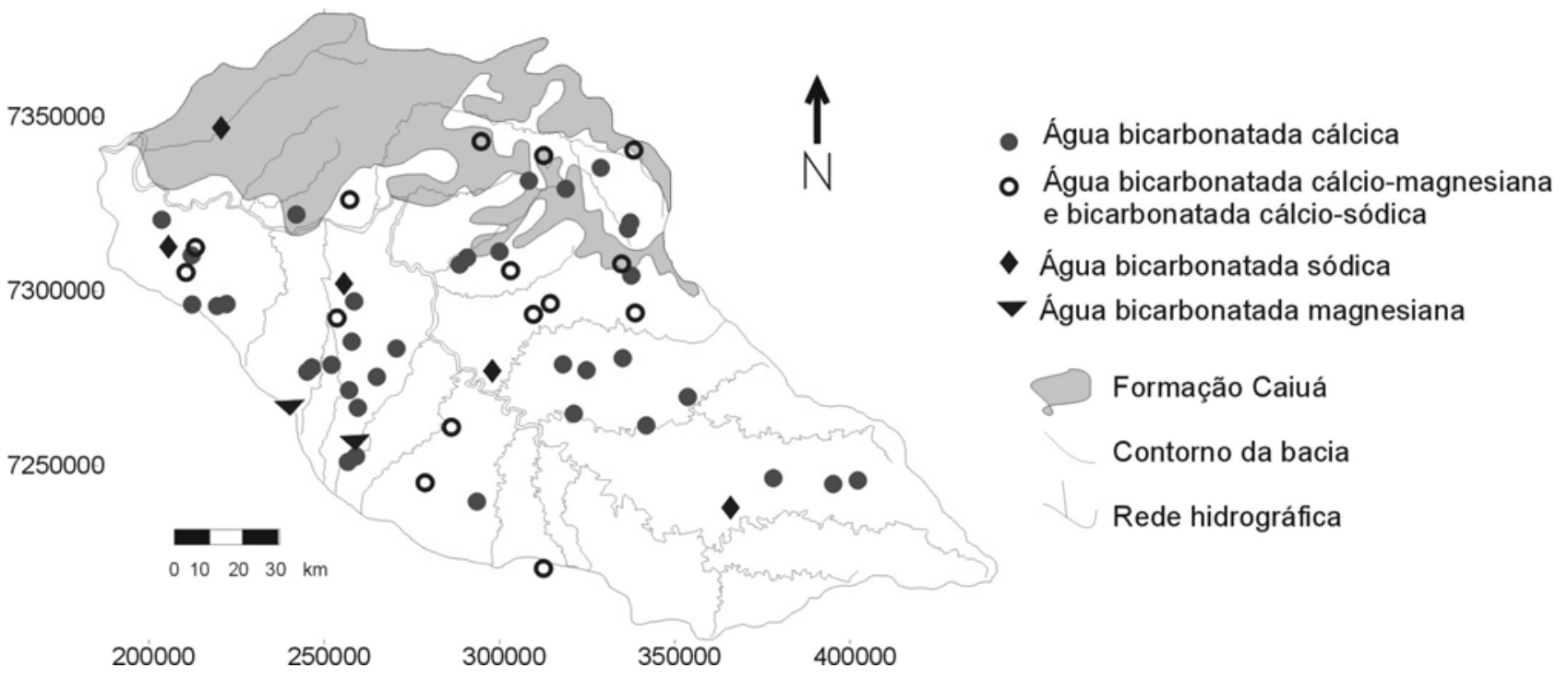

Figura 04: Distribuição das amostras na bacia do Piquiri, mostrando um zoneamento hidroquímico influenciado por estruturas de caráter regional.

As águas bicarbonatadas magnesianas ocorrem próximo ao limite com a bacia do rio Iguaçu, ao Sul, e em regiões de cotas mais elevadas altas e afastadas dos principais traços de elementos estruturais regionais. As águas bicarbonatadas sódicas são freqüentes nas proximidades da calha do rio Piquiri e ocorrem, possivelmente, devido à influência de estruturações geológicas regionais; 
esses poços foram perfurados em cotas topográficas mais baixas, o que, a priori, permite uma interconexão hidráulica com os aqüíferos inferiores, em especial com o Sistema Aqüífero Guarani.

As águas de composição mista, que englobam as bicarbonatadas cálcio-sódicas e bicarbonatadas cálcio-magnesianas, distribuem-se sem constituir um posicionamento definido na bacia hidrográfica, assim como os poços cujas águas são classificadas como bicarbonatadas cálcicas. É interessante destacar que as elevadas concentrações de flúor e de sulfatos podem torna-las inadequadas para o consumo humano, ainda que os poços secionem apenas as rochas efusivas da Formação Serra Geral.

Contribuições das formações suprabasálticas arenosas, notadamente a Formação Caiuá, são caracterizadas por uma relação $\mathrm{rNa}^{+} / \mathrm{rK}^{+}$inferior à unidade (BITTENCOURT, 1978 E 1993). Se houve, nos poços da porção noroeste da bacia do Piquiri, influência destes aqüíferos, ela é imperceptível em face da baixa salinidade daquelas águas. Pequena mistura de água de dissolução dos basaltos já leva a relação para valores superiores a 1,0. Nas águas relacionadas a basaltos a relação varia entre 18,02 e 2,02 e em poços sobre o Caiuá a relação varia entre 0.27 e 1,58 , sendo os valores mais elevados atribuídos a contaminações por águas dos basaltos (BITTENCOURT, 1993).

\section{CONCLUSÕES}

As águas subterrâneas captadas através de poços tubulares profundos nas rochas basálticas da Formação Serra Geral, na bacia hidrográfica do Piquiri-PR, Brasil, possuem como íon predominante 0 bicarbonato cujo teor médio é de 48,95 $\mathrm{mg} / \mathrm{L}$. O pH médio é de 7,32 sendo a média para STD 103,27 mg/L. A média de cloretos é de $1,39 \mathrm{mg} / \mathrm{L}$, atingindo um valor máximo de $6 \mathrm{mg} / \mathrm{L}$. O sulfato possui teor médio de $2,47 \mathrm{mg} / \mathrm{L}$, sem ultrapassar o teor de $6 \mathrm{mg} / \mathrm{L}$. O cálcio possui um teor médio de $9,78 \mathrm{mg} / \mathrm{L}$, sendo que $52,5 \%$ das amostras apresentam teores inferiores a $10 \mathrm{mg} / \mathrm{L}$ e 96,7 \% estão abaixo de $20 \mathrm{mg} / \mathrm{L}$. O sódio possui uma média de $8,49 \mathrm{mg} / \mathrm{L}$, sendo que $85,3 \%$ das amostras estão abaixo de $15 \mathrm{mg} / \mathrm{L}$. Valores incomuns de sódio nas águas do Sistema Aqüífero Serra Geral, acima de $55 \mathrm{mg} / \mathrm{L}$, foram detectados apenas em dois poços 74 perfurados no extremo oeste da bacia hidrográfica do Piquiri.

O principal processo geoquímico condicionador do teor dos macroconstituintes dissolvidos nas águas é a hidrólise dos silicatos do basalto e equilíbrio do carbonato de cálcio a pH alcalino. Com a depleção da quantidade de cálcio e magnésio dissolvidos, o aumento dos teores relativos em sódio é uma das conseqüências.

Definiu-se três classes significativas para as águas dos poços perfurados no sistema Aqüífero Serra Geral, na região de abrangência da bacia hidrográfica do Piquiri, a saber: 1) águas bicarbonatadas cálcicas $(62,2 \%$ das amostras); 2) águas bicarbonatadas cálcio sódicas e bicarbonatadas cálcio magnesianas (22,9 \% das amostras); 3) águas bicarbonatadas sódicas (11,4 \% das amostras). Essas águas são oriundas de aqüíferos sotopostos, principalmente o SAG, com possíveis influências também de outras unidades da Seqüência Paleozóica.

Sumarizando o observado pode-se dizer que os principais processos de condicionamento do quimismo das águas do aqüífero Serra Geral na bacia hidrográfica do rio Piquiri são: dissolução dos basaltos e equilíbrio com minerais secundários ; misturas com águas de aqüíferos sotopostos.

\section{BIBLIOGRAFIA}

BITTENCOURT, A. V. L. Sólidos hidrotransportados na bacia hidrográfica do rio Ivaí: Aplicação de balanços hidrogeoquímicos na compreensão da evolução de processos da dinâmica externa. São Paulo, 1978. Tese de Doutorado, Instituto de Geociências, USP

BITTENCOURT, A.V.L. Sobre a quantificação do intemperismo na Bacia do Rio Piquiri-PR. Boletim Paranaense de Geociências n. 41, 1993. p. 35-51

CELLIGOI, A. Aspectos hidrogeoquímicos da Formação Serra Geral em Londrina PR. In: CONG. BRAS. ÁGUAS SUBT., 8, Recife, 1994. Anais...Recife: ABAS. p. 425-433

FERNANDES, L.A. Tese de Doutorado, São Paulo, 1992. Instituto de Geociências, USP

FERREIRA, F.J.F Alinhamentos estruturais - magnéticos da região centro oriental da Bacia do Paraná e seu significado 
tectônico. Geologia da Bacia do Paraná. Reavaliação da potencialidade e prospectividade em hidrocarbonetos. Paulipetro - Consórcio CESP/IPT, São Paulo, 1982, p. 143-166

FERREIRA, F.J.F.; MORAES, R.A.V.; FERRARI, M.P.; VIANNA, R.B. Contribuição ao estudo do lineamento estrutural de Guapiara. In: Simpósio Regional de Geologia, 3, Curitiba, 1981. Anais...,v. 1,Curitiba: SBG . p. 226-240

FRAGA,C.G. Introdução ao zoneamento do sistema aqüífero Serra Geral no Estado do Paraná. . São Paulo, 1986. Dissertação de Mestrado. USP

FRAGA, C.G. Origem de fluoreto em águas subterrâneas dos sistemas aqüíferos Botucatu e Serra Geral da Bacia do Paraná. São Paulo, 1992. Tese (Doutorado) USP

FRITZ, B. Étude thermodynamique et modélisation des reactions hydrothermales et diagénétiques. Mém. Sciences Géologiques, n. 65, Strasbourg, 1981. $201 \mathrm{p}$.

HEM, J.D. Study and interpretation of the chemical characteristics of natural water U.S.Geol. Survey Bull. 1970, n.715. p.125139

HYPOLITO, R. Estudo experimental de alteração intempérica de diabásios.São Paulo, 1972. Tese (Doutorado). USP

LEVI, F.; MELFI, A.J. Geochemical and mineralogical studies on the first stages of wethering of basic and related rocks. 1972, Rev. Bras. De Geociências, n. 2(1), p. 1 - 7

LEINZ, V. Contribuição à geologia dos derrames basálticos do sul do Brasil. Boletim da Faculdade de Filosofia, Ciências e Letras, São Paulo, Geol. 5, 1949. 103p.
POPP, J.H.; BIGARELLA, J.J. Formações Cenozóicas no Noroeste do Paraná. Anais da Academia Brasileira de Ciências, 1975. n. 47 (supl.), p. 465-472.

REBOUÇAS, A.C. Sistema Aqüífero Botucatu no Brasil. In: CONG. BRAS. AGUAS SUBT., 8, Recife, 1994.

Anais...Recife: ABAS. p. $500-509$

REBOUÇAS, A. C. Potencialidades hidrogeológicas dos basaltos da Bacia do Paraná no Brasil. In: CONG. BRAS. GEOL., 30, Recife, 1978. Anais..., v. 6, Recife: SBG. p. 2963-1976

ROSA FILHO, E. F.; SALAMUNI, R.; BITTENCOURT, A. V. L. Contribuição ao estudo das águas subterrâneas nos basaltos no Estado do Paraná. Boletim Paranaense de Geociências, n 37, 1987. p. 22-52

RÜEGG, N. A. Aspectos geoquímicos, mineralógicos e petrográficos de rochas basálticas da Bacia do Paraná, São Paulo, 1969. Tese (Doutorado), USP SOARES, P.C., BARRETO, M.L.K., REDAELLI, R. Aplicação da Análise morfoestrutural em Semi-detalhe com fotos aéreas na Bacia do Paraná. In: SIMP. SUL REGIONAL GEOLOGIA,3, Curitiba, 1981. Anais... Curitiba: SBG.NSP. p. 217-225

SOARES, P.C., MATTOS, J.T., BALIEIRO, M.G., BARCELLOS, P.R., MENEZES, P.R., GUERRA, S.M.S., CSORDAS, S.M. Imagens de Radar e Landsat na Bacia do Paraná. In: SIMP. SUL REGIONAL GEOLOGIA,3, Curitiba, 1981. Anais... Curitiba: SBG.-NSP. p. 201-216

VIEIRA, A.J. Geologia do centro e nordeste do Paraná e centro - sul de São Paulo. In: CONGR. BRAS. GEOL., XXVII, São Paulo, 1973. Anais..., v. 3, São Paulo: SBG. p. 259 - 277 